\title{
PLAZAS FUERTES Y FRONTERAS ESTABLES EN EL PARAGUAY COLONIAL DE LOS SIGLOS XVII Y XVIII. EL CASTILLO DE SAN AGUSTÍN DE ARECUTACUÁ
}

\section{FORTRESSES AND STABLE BORDERS IN THE COLONIAL PARAGUAY IN THE 17TH AND 18TH CENTURIES. THE CASTLE OF SAN AGUSTÍN DE ARECUTACUÁ}

\author{
FRANCISCO CORRAL* \\ Instituto Cervantes de Palermo, Italia \\ dirpal@cervantes.es
}

\begin{abstract}
Un caso particular del control territorial que la Corona española ejerció en el continente americano lo constituye la Gobernación del Paraguay. Las amenazas que suponía el constante asedio de los pueblos indígenas que la circundaban obligaron a redefinir en varias ocasiones sus fronteras al tiempo que la población colonial fue despoblando y repoblando los núcleos periféricos. Como articuladores de este territorio se dispusieron en diferentes épocas castillos y fortalezas, estudiándose en este contexto el caso del de San Agustín de Arecutacuá, exponiéndose además su largo historial constructivo a partir de documentación extraída del Archivo Nacional de Asunción.
\end{abstract}

Palabras clave: San Agustín, Arecutacuá, Castillo, Paraguay, Fronteras.

The Governorate of Paraguay was a particular fact in the strategy for the control of the Hispanic American territory. The threat of the indigenous peoples forced the colonial administration to redefine its borders while the population settled and depopulated the peripheral areas. To that end, castles and forts were built to control the territory in diverse periods. In this article it is studied the castle of San Agustín de Arecutacuá as an example of this situation, developing its building history from documents extracted from the Archivo Nacional de Asunción.

Keywords: San Agustín, Arecutacuá, Castle, Paraguay, Borders.

* Con especial agradecimiento a Ignacio J. López Hernández, que ha revisado y actualizado el texto. 


\section{MARCO HISTÓRICO}

Contemplando con mirada generalizadora y comprensiva la historia del Paraguay Colonial, se observa que más allá y por encima (o por debajo) de los acontecimientos particulares, tuvieron lugar amplios procesos de expansión y de retracción que se fueron alternando regularmente y abarcaron periodos bastante largos. Retomando la conocida imagen del "Paraguay, corazón de América", se podría decir que el Paraguay Colonial manifiesta algo así como movimientos de "sístole" y "diástole" traspasados al territorio. La Colonia es una sociedad bastante inestable, en constante desasosiego y con tremendas dificultades para establecer sus perfiles, sus límites. A períodos de enorme expansión territorial siguen otros períodos de fuerte retracción territorial, económica y demográfica, en los que la nueva Provincia se reduce a un puñado de pobladores amenazados y recluidos en un limitado espacio. A grandes rasgos, esta sucesión periódica de flujos y reflujos poblacionales (sístoles y diástoles) puede resumirse así:

- Primer flujo: El grupo conquistador-expedicionario que se despliega desde el estuario del Río de la Plata hasta el pie del Altiplano.

- Primer reflujo: Tiene lugar con el retroceso general de las primeras expediciones, que encuentran refugio en Asunción, donde se concentra toda la población colonial tras abandonar Buenos Aires en 1541.

- Segundo flujo: Fundaciones desde Asunción. Esta expansión alcanza su límite en el año 1593, con la fundación de Santiago de Jerez, por Ruy Díaz de Guzmán.

- Segundo reflujo: El siglo XVII es una retracción continuada. En 1676 se abandona Villa Rica del Espíritu Santo y se despuebla toda su comarca. Hacia el final del siglo el área poblada llega a su menor extensión territorial, con el extremo norte situado en la línea Altos-Atyra-Tobati ${ }^{1}$.

- $\quad$ Tercer flujo: Fundaciones del Siglo XVIII. "En 1696, tras medio siglo de retracción territorial y demográfica, la fundación del pueblo de indios de Itapé marca el comienzo del fin de ese proceso regresivo... transcurrirán casi

1 "En el transcurso del siglo XVII, y hasta fines de la Revolución Comunera (1735) los habitantes de la Provincia del Paraguay se van a desenvolver dentro de un espacio muy reducido. En efecto, se puede considerar como poblados el área de Asunción y un arco irregular que se extiende al norte a través de las localidades de Limpio, Luque, Tobati, y por el sur a través de San Lorenzo, Ipane, Guarambare, Yaguarón. Otra zona poblada la constituye la zona de Villarrica, Caazapá, Yuty... Se puede considerar como habitada la zona comprendida entre Coronel Oviedo, San Estanislao, Curuguaty, pues en estas dos últimas se recogía la yerba". KEGLER KRUG, Anneliese: "La población del Paraguay a través de les censos de Azara y Aguirre", Revista Paraguaya de Sociología, 30, Mayo-Agosto 1974, p. 183. 
treinta años antes que otra fundación, la Villeta del Guarnipitán, confirme esa tendencia a la recuperación”’.

\section{EL CASTILLO DE SAN AGUSTÍN DE ARECUTACUÁ}

2.1. Qué es y qué testimonia un castillo

Un castillo es, en primer lugar, una obra militar defensiva. Es evidente que no construye un castillo quien avanza o ataca, sino quien se ve en la necesidad de defenderse. En segundo lugar, es una obra de frontera. Y en tercer lugar, un castillo, como construcción muy estable, pretende ser un medio de afirmación definitiva en el terreno. Bajo estas sencillas caracterizaciones, podemos concluir que cuando un grupo humano construye un castillo lo hace con la idea de defenderse ante la amenaza de enemigos que son más poderosos o que, al menos, le llevan la iniciativa. Pero ante tal amenaza, se hace patente la decisión de afirmarse en terreno y de poner un límite al retroceso, estableciendo una frontera sólida. La construcción de un castillo testimonia la expresión de una "voluntad de defensa, de no retroceder". No es ésta una actitud expansiva, pero tampoco lo es de nula iniciativa. En general, un castillo no se levanta ni en un avance ni en una retirada, sino en una situación intermedia; habitualmente en el momento límite, ya sea como conclusión de un periodo expansivo o como fin e interrupción de un retroceso. El caso concreto de los ejemplos existentes en Paraguay es modélico: Arecutacuá representa el final de un retroceso (el "segundo reflujo") mientras que Borbón y San Carlos marcan el límite de una expansión (el "tercer flujo").

\subsection{Antecedentes. El Siglo XVII}

La retracción territorial y demográfica del Siglo XVII, que hemos clasificado como el "segundo reflujo" de la Colonia, estuvo motivada por muy diversas y complejas causas que no nos detendremos a analizar en profundidad. Solamente citaremos las más evidentes:

a) La excesiva dispersión de los poblamientos de S. XVI en áreas territoriales demasiado extensas para las posibilidades demográficas reales ${ }^{3}$.

b) En opinión de Félix de Azara, las ordenanzas de Alfaro de 1612 provocaron a la larga la ruina económica y social de la Provincia. Opina Azara

2 VELAZQUEZ, Rafael Eladio: "Poblamiento del Paraguay en el Siglo XVIII", Revista Paraguaya de Sociología, 42/43, pp. 176-177.

3 "Las fundaciones del Siglo XVI habían sido avanzadas en el desierto o en tierras de indígenas aun no totalmente sometidos, separadas por grandes distancias las unas de las otras. Solamente así puede explicarse su gran área de dispersión, la acusada desproporción entre superficie y corta población" VELÁZQUEZ, Rafael Eladio: "Poblamiento...", op.cit., p. 176. 
que las célebres ordenanzas crearon trabas insuperables para el régimen de encomiendas y favorecieron, en cambio, a las reducciones jesuíticas.

c) La presión de la población nativa circundante, que se fue organizando militarmente para enfrentar a los recién llegados. Principalmente las tribus chaqueñas, de cultura paleolítica, tradicionalmente enfrentados a los Guaraní:

- La presión de los Guaycurú aumentó notablemente a partir de $1612 .^{4}$

- Los Mbayá norteños atacaron en el año 1661 Santa María de Fe (situada aproximadamente en la desembocadura del río Apa), y quedaron dueños de todo el Ytati con pleno dominio basta el río Jejuí. ${ }^{5}$

- Los Payaguá (habitantes de los ríos y expertos canoeros) en 1664 asaltaron Atyrá, Ypané y Guarambaré, haciendo huir a toda su población. En 1671 (31 de diciembre) tuvo lugar una nueva gran incursión con pillajes e incendios que abarcaron desde Tapuá hasta la hacienda jesuítica de Tacumbú y el valle de Lambaré. En 1672 una patrulla de 20 soldados fue emboscada y aniquilada, llegando la incursión hasta la actual Zeballos-cué con muerte o cautiverio de sus moradores. De nuevo en 1673 se produjo una importante incursión payaguá por el río Jejuí cayendo sobre Atyrá donde "mataron y apresaron 80 almas, y a un clérigo que interinariamente les administraba los sacramentos le dieron muerte". 6

d) Las incursiones de los bandeirantes paulistas que capturaron miles de indios guaraníes, obligando a los pobladores de las zonas periféricas de la Provincia a replegarse hacia el centro.

A causa principalmente de estas circunstancias históricas, el Siglo XVII se convirtió en una continua retirada de la población colonial paraguaya que ve reducirse progresivamente su territorio. E incluso cuando el Paraguay colonial vuelve a refugiarse en Asunción y una pequeña área circundante, como había hecho en los tiempos de la conquista, persiste como una pesadilla el "peligro guaycurú" que amenaza con liquidar completamente a la joven sociedad hispano-guaraní. Los Guaycurú llegaron a incursionar sorpresivamente hasta zonas muy próximas a Asunción. En 1674 las bandas sureñas y norteñas aliadas atacaron las estancias de los valles de Salinas y Tapuaguasú, sirviéndose del tradicional

${ }^{4}$ SUSNIK, Branislava: El indio colonial del Paraguay, Asunción, 1971, pp. 31-32.

${ }^{5}$ AZARA, Félix de: Descripción e Historia del Paraguay y del Río de la Plata, Buenos Aires, 1943, p. 137.

6 VELÁZQUEZ, Rafael Eladio: “La población del Paraguay en 1682”, Asunción, 1981, pp. 7-9. 
paso guaycurú de Arecutacuá. ${ }^{7}$ Ante una amenaza tan próxima, la Provincia se defiende a la desesperada recurriendo, incluso, a métodos tan drásticos como brutales: el día 20 de enero de 1678 el Gobernador Rexe Corvalán prepara una fingida boda entre el Teniente Gobernador, José de Avalos, y una hija de los principales Guaycurú. Venidos los Guaycurú a Asunción para celebrar las ceremonias, fueron acuchillados más de $300^{8}$. Como consecuencia de aquella masacre, parece que decreció considerablemente la presión de los Guaycurú sobre Asunción. En cambio, permanecía la amenaza de los Mbayá por el norte, de los Payaguá a lo largo del Rio, y de ambos en alianza combinando sus acciones.

Refiriéndose a los años 1697-98, un informe posterior de Diego de los Reyes Balmaseda, fechado el 24 de julio de 1719, dice: “... Governando esta Provincla D. Juan Rodríguez de Cota entró en aquellos valles por el mes de octubre un ejército populoso de otros enemigos infieles de numero de mas de dos mil guerreros mataron y rovaron dejandolos asolados en particular sucedio el frangente al sargento mayor del Presidio de los Altos que hallandose actualmente oiendo misa con dies y seis hombres de su esquadra entraron en la plaza del Pueblo seis u ocho indios enemigos acavallo le fue preciso montar con otros hombres no sabiendo lo que avia fuera y salir en seguimiento de ellos que lo fueron hachicando y de repente salieron los enemigos que estaban de celada en una montañuela y los cercaron y mataron cogiendoles los caminos y partes estrechas para que los soldados del Presidio de Tovati y demas que pudieron concurrir al socorro fuesen ympedidos y muertos..." 9

Para organizar una defensa efectiva de la Provincia, se hacía necesario controlar el río Paraguay, vía natural de los desplazamientos de los Payaguá y el camino más fácil para las incursiones de los Mbayá. Y para controlar el río era preciso dominar los "pasos" o accesos fáciles de desembarco y bien comunicados.

Si bien en ocasiones los Mbayá realizaban incursiones por zonas interiores alejadas de los ríos (en 1699 Tobatí tuvo que ser evacuado) el peligro más inminente para Asunción llegaba a través del río Paraguay, por el cual los Payaguá, diestros canoeros, penetraban hasta los alrededores de la ciudad, facilitando a veces el paso de los Mbayá con ocasión de sus alianzas. Repetidas veces se señala que el paso próximo más utilizado por los Payaguá es el de Arecutacuá. Por ello, el 21 de abril de 1697 el Gobernador Felipe Rexe Corvalán y varios miembros del Cabildo salen a reconocer el paraje de Arecutacuá, con la intención de fundar una Villa o, cuando menos, establecer una guarnición que proteja a la capital de nuevas incursiones. Pero desisten de su intento porque no encuentran lugar a propósito por estar todo inundado a causa de la creciente. ${ }^{10}$

${ }^{7}$ SUSNIK, Branislava: El indio colonial... op.cit., p. 43.

${ }^{8}$ AGUIRRE, Francisco de: Diario, Buenos Aires, 1949, t. II, segunda parte, p. 441.

${ }^{9}$ ANA (Archivo Nacional de Asunción) MG 1138 (908).

${ }^{10}$ NOGUES, Alberto: "El castillo de Arecutacuá", Anuario de la Academia Paraguaya de la Historia, Vol. 8-9-10, 1963-65, p. 57. 
Los Payaguá estaban establecidos en tres núcleos principales a lo largo del río Paraguay: el norteño tradicional, el intermedio a la altura de Arecutacuá, y el sureño ya cerca del Pilcomayo ${ }^{11}$. Contra este último poblamiento payaguá, el más próximo a Asunción, se dirigió la acción del Gobernador Reyes Balmaseda quien: "hallándose dos tolderías en las cercanías de la ciudad las asalto el día 18 de febrero de 1717. Abaleó bastantes indios y apresó algunas familias que remitió a Misiones"'12.

\subsection{Construcción y establecimiento}

Como hemos señalado, la provincia del Paraguay se ve sometida durante el siglo XVII a una permanente presión que llega a su punto álgido con el final de siglo (se ha señalado como el momento de máxima retracción la evacuación de Tobatí en el año 1699). Pero hacia esas mismas fechas comenzaban ya a hacerse evidentes algunos síntomas de reacción. La fundación de Itapé (1696) y más tarde la de Villeta (1714) ${ }^{13}$, las primeras después de casi un siglo de retracción, no son fenómenos aislados, sino el inicio de un periodo expansivo que abarcará todo el siglo XVIII, al final del cual la Colonia alcanzará a poblar un área inmensamente mayor de la que ocupaba hacia el 1700. La construcción del castillo de Arecutacuá en 1717 pone de manifiesto la voluntad decidida de defender el territorio, de no retroceder ya más, y coincide con el inicio de la recuperación de la Colonia; es consecuencia de la iniciativa recuperada por la Provincia, y es a la vez un factor importante para que esa iniciativa llegue a cristalizar en una efectiva expansión. En párrafos anteriores señalábamos que la construcción de un castillo suele ser prueba de que ha llegado a su límite un proceso de expansión o de retracción. En este caso, la edificación de San Agustín de Arecutacuá, manifiesta con precisión que ha llegado a su fin aquel retroceso constante a que la Provincia del Paraguay se había visto obligada durante todo el siglo XVII.

El 15 de marzo de 1717, el Gobernador Diego de los Reyes Balmaseda propone al Cabildo: ..."para la defensa universal de la Provincia assi de otros indios enemigos fronterizos de tierra de varias naciones como de los Paiaguas que havitan el Rio arriva i le traginan continuamente y asi mismo por lo no menos considerando: que son los Mamelucos Portugueses de la Villa de San Pablo que pudieran yntentar por el otro Rio en embarcaciones ejecutar ymbasion en esta Provincia para cuio reparo es el único y mas presiso y esempcial medio que ha considerado y determinado su señoria poner y fabricar un castillo en el otro passo de Arecutagua con dos

\footnotetext{
${ }^{11}$ SUSNIK, Branislava: El indio colonial..., op.cit, p. 122.

${ }^{12}$ AGUIRRE, Francisco de: Diario, op.cit. t. II, p. 474.

13 Vid. Nota 2.
} 
piessas de artilleria de las que ai a presente y mantener la guarnicion necesaria de soldados españoles"14.

La opinión del Cabildo y de los Sargentos Mayores de las milicias es favorable a la propuesta de Reyes Balmaseda, y sin la menor dilación se da comienzo a la construcción del castillo. El 20 de marzo del mismo año 1717 se informa ${ }^{15}$ haber establecido la planta del edificio en el paraje de Arecutacuá, a una legua del arroyo Yabebuiri, contando con una guarnición de 150 soldados, e indios que se turnan por meses. Hay también dos chalupas para acudir a otros lugares y patrullar el rio. En el mismo informe se considera que "siendo otro parage la llave $i$ principal defensa i resguardo de los pasos del enemigo”, las guarniciones próximas carecen ya de función, y son abandonadas las de Altos y San Roque, confiando en la importante fuerza establecida en Arecutacuá. Como "castellano de la obra" se cita a D. Andrés de Orúe y Zarate. Y ya en 1718 hay noticias de que está siendo construida una fortificación al otro lado del río ${ }^{16}$.

Una descripción del castillo ya terminado, fechada el 19 de abril de 1719, lo describe como "Castillo de muralla fuerte de tierra gruesa de siete a ocho varas de alto, con 6 torreones" ${ }^{\prime 17}$. La fuerza está constituida por 40 mulatos, 80 indios auxiliares y 408 españoles. Se señala también la existencia de una pequeña fortificación al otro lado del rio, en tierra chaqueña, dotada con veinte soldados con sus fusiles, dos cañones pedreros y una chalupa.

En su informe a la Corona, fechado el 24 de julio de 1719, el Gobernador Diego de los Reyes Valmaseda dice: “... resolvi la fundacion de un castillo en el parage que llaman de Arecutacuá rio arriba distante de esta Ciudad dies y seis leguas poco mas o menos cuio sitio es uno de los mas seletos y de mejor territorio sobre la propia costa y ribera paso principal por donde el enemigo de tierra frecuentava diferentes ejercitos numerosos fomentado y coligado con la nacion Paiagua en sus transportes con los Cuales marchavan y executavan Imbasiones en los valles que llaman de la cordillera sin ser sentidos en sus pasages... que desde que se fundo otro Castillo no son tan osados y frequentes como antes con desaogo y libertad, ni pueden ser, respecto de que siempre que lo han intentado han sido rechasados mediante el desvelo y cuidado que se tiene sobre ellos y de un fuerte que se puso a la otra vanda sobre la ribera del mismo rio donde bien atrincherados todas las noches hacen guardia dies $y$ seis y veinte hombres con buena fusileria y dos pedreros bien arnunicionados y las mas de las noches las chalupas aplomadas en medio rio .. Hame costado poner en el referido estado en que se halla bastantes desvelos personales y costo en la mayor parte de mi corto caudal... y suplico postrado a sus reales pies se digne con vista de otros autos de aprovar y confirmar esta mi determinación concediendo a otro castillo

\footnotetext{
${ }^{14}$ ANA. S.H. Vol. $89, \mathrm{n}^{\circ} 1$

${ }^{15}$ Ibídem.

${ }^{16}$ Ibíd.

${ }^{17}$ Ibíd.
} 
y su plaza los honores que fuere de su real gratitud pues no solo sirve de freno al enemigo infiel de Barbaras naciones, sino que tambien lo puede ser para rechazar y castigar a los mamelucos de San Pablo en caso de que pretendan introducirse con embarcaciones por dicho Rio y asi mismo que el beneficio que ha redundado de que a su abrigo sean poblado y ban poblando los españoles sus chacaras y estanzuelas por ser los valles pingües y el territorio de mucha conveniencia que estaban abandonados por el terror deotros enemigos" 18 .

La fundación de San Agustín de Arecutacuá fue aprobada por real cédula de 28 de agosto de 1721 .

\subsection{Derrumbe y reconstrucción}

El castillo de San Agustín de Arecutacuá, construido en 1717 no se mantuvo en pie durante mucho tiempo. Sus murallas "de tierra fuerte" aguantaron unos cinco años, hasta que las aguas del río Paraguay desbordado las arrasaron. El día 23 de mayo de 1723 informan desde Arecutacuá que "la cresiente tan grande a llevado ya dos lados del fuerte uno a la parte del Rio arriba y otro a la parte del poniente que es adonde se arrima más la cresiente”. Y pocos días después comunican que el agua "ya entra hasta la cruz del patio y en lo demas espera caerse todo segun esta el Rio"19.

Por aquellos años, en la Provincia se estaban produciendo acontecimientos importantes y sangrientos. Son los años de la Revolución Comunera, y todas las energías se emplean apasionadamente en dirimir cuestiones internas. Es la causa probable de que el Castillo de San Agustín de Arecutacuá no fuese reparado con la celeridad necesaria. Aprovechando esta circunstancia, los indios fronterizos fueron mucho más allá de las escaramuzas habituales y lanzaron un ataque en toda la regla contra la fortificación (o lo que de ella quedara), ya que fue "cercado y acomentido el alojamiento de españoles mulatos libres y sus familias que en el asisten desde que se arruino en el Govierno proximo pasado el Castillo y fortale$z a$ "20 Del ataque resultaron dos españoles heridos y un mulato muerto. El ataque fue rechazado, por fortuna para la Provincia. De haber logrado los atacantes su objetivo, podemos imaginarnos el peligro cierto para la propia Asunción. Ya que, por una parte, la situación era de gran debilidad interna por causa de las luchas comuneras, y por otra parte es evidente la decidida intención de las tribus fronterizas al cercar y atacar la más fuerte posición defensiva de la provincia. De haber caído Arecutacuá, la existencia misma de la Colonia se habría visto seriamente amenazada.

\footnotetext{
${ }^{18}$ ANA. MG 1138 (908)

${ }^{19}$ ANA, SH, vol. 101, $\mathrm{n}^{\circ} 4$.

${ }^{20}$ ANA, SH, vol. 112, no 3 .
} 
Ante esta peligrosa perspectiva, a más de dos años de su derrumbe, el día 28 de julio de 1725 el Gobernador Martín de Barúa ..."determinó pasarse reconocimiento de utilidad del Castillo y fuerte arruinado de San Agustín del cual solo se guarda la memoria de sus vestigios por averselo robado el Rio en su gran creciente proxima passada" ${ }^{21}$ y ordena que se proceda a reconstruir la fortificación pero no en el mismo sitio, sino en un lugar algo más alto para evitar el peligro de las crecientes, concretamente "cuatro cuadras al centro de su primitiva ubicación" 22 . Lo que se llevó a cabo con bastante rapidez, ya que el 9 de agosto de 1726 el Sargento Mayor Ignacio Pereira, encargado de la obra, informa que "se halla ya conclusa" y al día siguiente describe la construcción como "sinquenta baras en cuadro con veinte viviendas cubiertas de teja de (roto) dos cubos capaces de alojarse diez soldados en cada uno y governar sus armas con desahogo, y el edifisio de piedra y varro con simiento en parte de dos varas y en otras de una vara y media, y un corral para la cavallada (...) la altura tres baras y del corral dos baras..."23. El gobernador, Martín de Barúa, informa al Rey de la reconstrucción de Arecutacuá ese mismo mes agosto de 1726.

La obra fue realizada con mayor eficiencia y solidez, en "piedra y barro"; y, de hecho, este Arecutacuá reconstruido se mantuvo en pie y cumplió su importante misión durante más de 13 años, hasta que en 1738 Fernández Montiel hubo de extender su "certificado de defunción"24. Fue, sin duda, la construcción militar más importante que hasta entonces se había realizado en el Paraguay, sólo superada más tarde por Borbón y San Carlos durante toda la época colonial. Así lo subraya un informe del Cabildo en 1726: "hoy se halla acabado perfectamente con tal materia y forma que en todas estas provincias, en el centro de ellas, no hay otra que pueda ser de igual formación y permanencia por ser de piedra capaz de ser labrada por cantería y de resistir al enemigo" 25 . No obstante, el dibujo reproducido por Gutiérrez ${ }^{26}$ es evidentemente una imagen ideal o convencional que no guarda más parecido que el sentido genérico de "castillo" con la descripción antes citada del edificio de San Agustín de Arecutacuá.

Durante su existencia tuvo que hacer frente a momentos difíciles y situaciones apremiantes. Coincidiendo de nuevo con las sangrientas luchas internas que constituyeron el último episodio de las Revoluciones Comuneras, durante los años 1735 y 36, se intensificaron las acciones de los indios fronterizos. El Sargento Mayor Ramón Benítez informa con fecha 5 de mayo de 1736 las "continuas

${ }^{21}$ Ibídem.

${ }^{22}$ GUTIERREZ, Ramón: Evolución urbanística y arquitectónica del Paraguay (15371911), Resistencia, 1978, p. 19.

${ }^{23}$ ANA, SH, vol. 112, no 3

${ }^{24}$ NOGUES, Alberto: "El castillo...", op. cit., p. 63.

${ }^{25}$ GUTIERREZ, Ramón: Evolución urbanística..., op. cit., p. 20.

${ }^{26}$ Ibídem, p. 37. 
traisiones" de los indios durante los dos últimos años: entre otras cosas "devajo de paz confederados con los de río arriva mataron siete u ocho mulatos de la Plaza del Castillo de Arecutagua y cautivaron toda la familia"27 en total se llevaron cautivas unas 60 personas. En el informe previo al "acta de defunción" del castillo, el 28 de junio de 1738, el castellano Domingo Cabrera del Valle pide que se traslade la guarnición; dice que son pocos, están en la miseria, y su función defensiva es nula. El Mariscal de Campo Sebastián Montiel informa por su parte que Arecutacuá fue muy útil para cerrar el paso a los enemigos pero que ya los indios utilizan otros pasos. Insiste asimismo en que el castillo ya fue abandonado temporalmente "durante las operaciones de los enemigos populares y voz comun", en clara referencia a las revueltas comuneras. El Cabildo, por su parte, aconseja también el abandono del Castillo ${ }^{28}$.

Según el testimonio de Aguirre, al fundarse Emboscada (1742), Arecutacuá fue reconstruido de nuevo. Pero este dato no aparece confirmado en documentos. Evidentemente, en 1738, bien pasadas las revueltas comuneras, la recuperación de la Provincia era ya un hecho. No tenía sentido mantener una defensa tan próxima como San Agustín de Arecutacuá. La amenaza de los Payaguá estaba ya bastante disipada, tanto es así que en el 1740 comenzaron a firmarse las paces ${ }^{29}$. Paces que, evidentemente, los Payaguá aceptaban no de buena gana, sino forzados por las circunstancias que les imponían los nuevos pobladores. El Gobernador Jaime Sant Just firmó el 26 de mayo de 1753 las paces definitivas con los Payaguá. Paces que, como suele ser habitual, eran realmente una rendición más o menos honrosa, ya que en ellas se establecía:

- "Primte.: que aran entregar todos los cautivos sin interés alguno, y que por ahora se les permita el que puedan vender los cautivos del pueblo de Ittati y de otras Prov as si los tubieren.

- Itte.: Cuando vajen de sus tolderias a la ciudad han de pedir pasaporte en Arecutacua y pasados tres días han de volver.

- Itte.: Si quieren vivir más cerca han de pedir autorizacion al Gobierno señalando el lugar donde se establecen, y no moverse sin permiso escrito, $y$ siempre sin armas.

- Itte.: No han de vajar mas abajo del presidio de San Marcos.

- Itte.: Sobre todo no han de hacer daño a las embarcaciones de este Comercio ni a los guaranies, ni a ninguna otra por de Provincia extraña que sea, "y finalmente han de observar y guardar todos los estatutos que les impuso su antecesor el Señor Don Rafael de la Moneda”. ${ }^{30}$

\footnotetext{
${ }^{27}$ ANA, SH, vol. 127.

${ }^{28}$ ANA, SH, vol. 119, no 14.

${ }^{29}$ AZARA, Félix de: Descripción..., op.cit., p. 143.

${ }^{30}$ ANA, SH, vol. 127, n 7 , f. 1-2.
} 
El mismo Gobernador Jaime Sant Just acordó también las paces con los Mbayá el 15 de marzo de 1760, estableciendo como límite infranqueable para estas tribus el rio Manduvirá ${ }^{31}$.

Aunque el peligro más serio para la Provincia puede considerarse definitivamente conjurado a partir del sometimiento que suponen las paces firmadas, se mantuvo, no obstante, una guardia permanente en Arecutacuá, como lo demuestra el curioso encargo hecho al cabo de la Guardia de Arecutacuá el día 12 de septiembre de 1765 (prueba de la absoluta escasez de materiales y de metales en la Provincia): "El Cavo de la Guardia de Arecutacua en consorcio con Gabriel Irrazabal, hara sacar todos los clavos, y demas fierros que se hallan en el armage que (roto) fabricar el difunto Señoy Gov.or y sacandolos con todo el cuidado y prolijidad, los hara acomodar en el bote; y el otro cavo tomara recibo con toda individualidad del otro Irrazabal de todo lo que le entregare, quedandose en el y me dara quenta con la misma individualidad, apuntando quantos clavos, quantos trosos de madera, y todo lo demás por su orden con toda claridad"32.

En 1790 había una guarnición de 19 soldados y un sargento ${ }^{33}$ y a fines del año 1793 todavía se mantenía un cañón de a ocho ${ }^{34}$. Incluso en el año de 1803 , no se habían abandonado del todo las precauciones contra posibles incursiones chaqueñas, manteniendo "siete u ocho soldados inclusive el oficial" 35.

Como ya señalamos, la construcción del Castillo de San Agustín de Arecutacuá señala el momento límite en que la retracción territorial de la Provincia llega al máximo y se impone la necesidad de resistir a toda costa para mantener el escaso territorio dominado. Para ello, era imprescindible conseguir la seguridad del control del río Paraguay. El Castillo de Arecutacuá fue un bastión fundamental para dominar el río e iniciar la recuperación y expansión de la Provincia que tuvo lugar a lo largo del siglo XVIII. Una vez alejado el peligro, Arecutacuá perdió su valor defensivo y su interés estratégico.

\subsection{Gastos y abastecimiento}

El desamparo de la Provincia del Paraguay por la Metrópoli no es un tópico al uso. Ningún subsidio de la Real Hacienda llegó para aliviar el permanente estado de guerra en que se defendía este territorio. No solamente el servicio militar (que ocupaba a los hombres durante varios meses al año) carecía de la menor remuneración económica, sino que además los gastos de avituallamiento y

\footnotetext{
${ }^{31}$ AGUIRRE, Francisco de : Diario, op.cit., p. 520.

${ }^{32}$ ANA, NE, vol. 558, f. 90

33 ANA, NE, vol. 3374.

34 ANA, NE, vol. 593, f. 116.

${ }^{35}$ ANA, NE, vol. 3398.
} 
manutención habían de ser sufragados directamente por los propios pobladores de la Provincia que a la vez eran sus defensores.

\subsubsection{Construcción}

Los gastos derivados del emplazamiento y construcción en 1717 del Castillo de San Agustín de Arecutacuá fueron cubiertos por el Cabildo y el Gobierno a base de recaudar donativos entre los habitantes de la Provincia. En oficio de 18 de marzo de 1717 el Gobernador Reyes Balmaseda urge a los vecinos "para que por via de donativo boluntario concurran a fomentar con los medios y efectos que pudieren y assi mesmo se hara saver a las demas personas de esta Republica ciudad y provincia discurriendose los mas medios arbitrarios permitidos para que todos se dediquen y combiertan (ilegible) sin que de ello resulten perjuicios a los reales haveres ni a ningun vasallo ni molestia ni agravio". Respecto al elemento humano necesario para la obra de construcción, "se pedira al $R$. P. Provincial de la Sagrada Religion de la Compañia de Jhs. auxilio de sinquenta indios de travajo para que por via de Mita concurran asta la perfecta conclusion de otra fabrica" ${ }^{36}$.

No pasado un mes, Reyes Balmaseda insiste en un nuevo bando pidiendo a los vecinos su aporte y ofreciendo comunicárselo al Rey: “...pide y exorta a cada uno de los vecinos feudatarios, moradores estantes y havitantes de la otra ciudad y provincia para que con la consideracion de esta representacion ofresca un donativo boluntario y gratuito segun su posibilidad y medio y especialmente el que tubiere ganado bacuno que es del que mas se necesita para la manutencion de los operarios de la otra fabrica y conservacion de los soldados que estan guarneciendo y guarneceran en lo de adelante el otro Castillo que de hacerlo asi se dara su Magestad por bien servido a quien dara quenta de este especial servicio que le hicieren" ${ }^{37}$.

Como es natural, los donativos salieron de aquellos que detentaban el poder económico, pues ellos eran también los más perjudicados por las incursiones depredatorias de los indios; el propio Reyes Balmaseda predica con el ejemplo y abre la lista de aportaciones entregando 500 cabezas de ganado.

No obstante, el que una obra de tal envergadura pudiera erigirse y mantenerse tan numerosa guarnición a base de donativos voluntarios, sólo puede explicarse considerando que se trataba de una situación de emergencia realmente grave, ya que la existencia misma de la Provincia se encontraba amenazada, y cada uno de sus habitantes sentía próximo el peligro. Así lo confirma un acuerdo del Cabildo el 29 de mayo de 1717, en el que se ofrecen los bienes de la Ciudad, y se afirma “... lo conven.te q.e es al Servicio de Ambas Mgdes y universal defensa destas Prov.as la fabrica del Castillo de Arccutagua y el que se acabe perfectam.te y su

\footnotetext{
${ }^{36}$ ANA, SH, vol. 89, nº 1 .

37 Ibídem.
} 
conservac. on y perman. a para cuio efecto se necesitan algu.s medios q.e podra esta Ciu.d de sus propios y rentas hazer algun suplem.to y socorro..."38. El 8 de marzo de 1718 San Agustín de Arecutacuá contaba con una guarnición de 408 españoles, más 80 indios auxiliares y 40 mulatos libres; en total 528 hombres $^{39}$. La manutención de tan numerosa fuerza había de resultar necesariamente costosa. Por ejemplo, en poco más de un año, de marzo de 1717 a mayo de 1718 , se consumieron ${ }^{40}$ :

- 905 cabezas de ganado

- 52 tercios de yerba

- 8 arrobas de tabaco

- 4 arrobas de sal

- 24 arrobas de sebo

Entre los gastos no se citan sueldos, ya que la obra material debió realizarse en su totalidad con indios en régimen de mita. Es lógico que el costoso mantenimiento de la nutrida guarnición del Castillo de Arecutacuá comenzara a constituir un grave problema a partir del momento en que el peligro dejo de ser inminente y los "donativos voluntarios" comenzaron a escasear. Así el 15 de enero de 1722 el Sargento Mayor Sebastián Duarte califica a sus soldados de "pobres miserables" y advierte que ya no tienen nada para comer y que los lugares poblados se encuentran a más de 12 leguas. El entonces Gobernador, José de Antequera, le envía 10 reses como ayuda de urgencia ${ }^{41}$. Viendo la lamentable situación de penuria que sufría la guarnición, y careciendo de medios para acudir a su sustento, el mismo "Gobernador comunero", Don José de Antequera y Castro "pide parecer al Cavildo y a varios vecinos de si sera conveniente la permanencia del Fuerte de S. Agustin de Arecutagua y los medios para su subsistencia. El Cavildo fue de parecer se despoblase; pero la maior parte de los militares vocales fueron de sentir se mantuviese por mui util para contener a los Yndios Ynfieles del Chaco..." 42

- El Cabildo apoya su opinión de que el castillo sea abandonado en varios motivos específicos ${ }^{43}$ :

- Los indios cruzan por otros "asequiones".

- No se han establecido pobladores junto al castillo porque los terrenos son pedregosos.

- La Provincia se encuentra en un "miserable estado de pobreza" lo que hace muy difícil mantener la guarnición.

\footnotetext{
${ }^{38}$ ANA, Actas del Cabildo de Asunción, vol. 16, f. 185-186.

${ }^{39}$ ANA, SH, vol. 89, $\mathrm{n}^{\circ} 1$.

${ }^{40}$ Ibídem.

${ }^{41}$ ANA, SH, vol. 101, no 4.

${ }^{42}$ Ibídem.

${ }^{43}$ Ibid.
} 
Seguramente a raíz de estos informes, y ante la imposibilidad de mantenerlo, tuvo lugar el abandono temporal del castillo durante más de dos años tras su derrumbe, como señalábamos en el apartado anterior.

\subsection{2. ¿Creó Antequera el Ramo de Guerra?}

Según Francisco de Aguirre, el Gobernador Rafael de la Moneda consiguió establecer el Ramo de Guerra hacia el año $1744^{44}$. Sin embargo, existen motivos para sospechar que dicho Ramo existía en la práctica mucho tiempo antes, y que lo inició formalmente el Gobernador José de Antequera y Castro. En el informe antes citado, donde el Cabildo y los jefes militares dan su opinión sobre la conveniencia de mantener o abandonar Arecutacuá, los vocales militares, partidarios de la permanencia del castillo, sugieren: .."y que para la permanencia de este Fuerte y los demas y sus abitantes se pencionase a cada chacarero con 2 libras de tavaco al año a los vezinos de Villa Rica con un tercio de yerva de cada ciento y a las embarcaciones de doze 14 mil a. que salieren de este puerto con 200 a. de yerva y a las carretas que salian fuera de la Provincia a ocho ps. a cada una y que con estos arbitrios se fundase un Ramo de Guerra que hasta entonces no le havia havido formal; persuadian al Gov. para la exacci5n de las 200 a. que assi lo havia verificado su antecesor D. Diego de los Reyes. Por fin el Gov. Antequera resolvía se diese cuenta a la Real Audiencia"45. Esto sucede en el año 1722, y del documento hemos de concluir que fue Antequera quien propuso a la Real Audiencia la creación del Ramo de Guerra. Refuerza esta suposición el hecho de que pocos años más tarde, en un oficio del 28 de julio de 1725 (casi 20 años antes de la supuesta creacion oficial por Rafael de la Moneda) el Gobernador Martín de Barúa diga con motivo de la reconstrucción de Arecutacuá: "por no aver efectos en el Ramo de Guerra"46 La frase testimonia la existencia oficial del citado Ramo de Guerra en la Gobernación provincial.

Probablemente, la interpretación mas correcta sea que el impuesto interno existia seguramente por lo menos desde los tiempos del Gobernador Diego de los Reyes Balmaseda ${ }^{47}$, que José de Antequera le confirió la entidad de Ramo de Guerra y propuso a la Real Audiencia su instauración oficial; y que Don Rafael de la Moneda estableció su forma definitiva. Es lógico, por otra parte, que la contribución obligatoria para la defensa de la Provincia, que fue el Ramo de Guerra, naciera en los años de mayor amenaza externa, y no en 1744, suando ya

${ }^{44}$ AGUIRRE, Francisco de: Diario, op.cit., p. 511.

${ }^{45}$ ANA, SH, vol. 101, $\mathrm{n}^{\circ} 4$.

${ }^{46}$ ANA, SH, vol. 112, $n^{\circ} 3$.

${ }^{47}$ Una de las acusaciones contra Reyes presentada por Torres Cardenas en la Real Audiencia fue: "Que impuso la gavela de 3 arrobas por cada 20 cargas que al estilo del país es un treinta por ciento" (según otros cálculos solo un 3\%) 
el peligro era mucho menor y la Provincia iniciaba su expansión. Así parece deducirse de un informe de fecha 5 de septiembre de 1795, en el que los dueños de buques afirman: .." que el Ramo de Guerra que se denomina Municipal de esta Provincia es exigido y se establecio por el señor Don Rafael de la Moneda; o si antes estubo ya establecido, le dio nueva forma el expresado señor siendo Gobernador de esta Provincia por los años del Quarenta y dos quarenta y seis del presente siglo"48.

\subsubsection{Reconstrucción}

Cuando el Gobernador Martín de Barúa decide en el año de 1725 reconstruir el Castillo de San Agustín de Arecutacuá, la situación económica de la Provincia seguía siendo la misma que habíamos señalado con referencia a la época de su primera construcción: ningún subsidio podía esperarse de la Metrópoli para acudir a los gastos defensivos de la Provincia. Martín de Barúa parece confiar en la improvisación para aportar los medios necesarios en la reconstrucción del castillo: "se determinara el mejor arbitrio que se pudiere y permitiere el estado y posibilidad de la tierra sin gravamen y perjuicio de la Real Hacienda y de los vezinos por no haber efectos en el Ramo de Guerra ni otro destinado para estos menesteres" 49. Terminada la reconstrucción, el 9 de agosto de 1726, el Sargento Mayor Ignacio Pereira informa que se han consumido 656 reses, de las cuales el propio Gobernador Martín de Barúa aportó 500. El gasto total de la obra se cifra en 3.954 pesos corrientes de a ocho ${ }^{50}$.

\subsection{Una curiosa petición}

Probablemente Martín de Barúa no sólo aporto casi todas las reses consumidas, sino también la mayor parte de los otros gastos de construcción. $\mathrm{O}$ al menos, ese merito se atribuye él mismo en un informe al Rey fechado el día 30 de Agosto de 1726, en el que da cuenta de haber reconstruido el Castillo de Arecutacuá a sus expensas y pide como recompensa ..." que se le exonere del servicio en este govierno". El día 1 de octubre se acusa recibo en la Corte, y se le informa de que el Rey ha dispuesto lo conveniente y se lo ha comunicado al Virrey ${ }^{51}$. Parece que Martín de Barúa no se sentía precisamente feliz como Gobernador del Paraguay. Podría tener sus motivos personales que desconocemos, pero también podemos imaginar los motivos históricos: Revolución Comunera en plena efervescencia, acentuada pobreza de la Provincia, amenaza de las tribus indígenas circundantes, etc.

\footnotetext{
${ }^{48}$ ANA, NE, vol. 511, $\mathrm{n}^{\mathrm{o}} 11, \mathrm{f} .1$.

49 ANA, SH, vol. 112, no 3 .

50 Ibídem.

51 Ibídem.
} 


\subsection{Poblamiento}

Ya hemos señalado anteriormente que la guarnición de Arecutacuá constituía una importante fuerza defensiva, muy numerosa tratándose de una posicíon bastante alejada de villas o lugares poblados: 150 soldados más indios auxiliares en 1717, y 528 hombres en marzo de 1718. Pero conviene considerar ahora la composición de ese grupo humano.

De los 528 hombres que hay en 1718, 408 son españoles, 80 son indios auxiliares y 40 son mulatos libres $^{52}$. Sabemos que los indios se encontraban allí trabajando por vía de mita en la obra de la construcción y que habían sido enviados por los jesuitas; hemos de suponer que estos indios se reintegraron a las reducciones una vez concluida totalmente la obra. Los españoles probablemente hacían guardias por turnos y la mayoría residirían en otros lugares. En cambio, los mulatos libres parece que llegaron a asentarse en el castillo e incluso formaron desde el principio una pequeña población permanente con sus familias. Así se expresa en el informe de 8 de junio de 1723, donde, informando sobre el derrumbe del castillo, Juan José Montiel dice: ..."por haber caido la pared del cubo que esta entre poniente y sur abriendo veintisiete varas lo caido y anegando por esta parte tres ranchos de la vivienda de los mulatos libres que con sus familiares están agregados en este castillo" 53 . Al año siguiente, el 16 de mayo de 1724, el Gobernados José de Antequera ordenó: "Se pusiese el reparo segun lo mas conmodo que se pudiera para el resguardo de las familias de mulatos libres que tienen poblados hasta tanto que con la bajada del Rio se conociese parage conmodo en que se pueda poner"54.

Mucho más interesante y de mayor alcance es la disposición por la que el Gobernador Martín de Barúa determinó la reconstrucción del castillo el día 28 de julio de 1725. En ella ordena que..." por la escasez de indios en los pueblos para operarios con la mortandad y enfermedad dellos de la epidemia Gral. que se ha padecido y padece al presente, recogan los mulatos libres que ai en la provincia para que asistan en la fábrica hasta su conclusión"... 55.

\subsection{Precedente de San Agustín de la Emboscada ${ }^{56}$}

Es indudable, pues, que en San Agustín de Arecutacuá existía una importante población de mulatos libres desde su fundación, incrementada fuertemente por la

\footnotetext{
${ }^{52}$ ANA, SH, vol. 89, $\mathrm{n}^{\circ} 1$.

${ }^{53}$ ANA, SH, vol. 101, $\mathrm{n}^{\circ} 4$.

54 Ibídem.

${ }_{55}$ ANA, SH, vol. 112, no 3.

${ }^{56}$ Una información muy completa sobre este tema ha sido recopilada por BLUJAKI, Agustín: Pueblo de pardos libres. San Agustín de la Emboscada, Asunción, 1980.
} 
disposición de 1725 en que Martín de Barúa ordenó llevar a todos los mulatos libres de la Provincia para la reconstrucción del castillo.

La versión de Azara acerca de la fundación del pueblo de San Agustín de la Emboscada, dice así: "Rafael de la Moneda viendose muy acosado de los barbaros Guaycurús que atacaban hasta las chacras de la capital tomó una porción de gente amparada, negra y mulata, y con ella fundó este pueblo de San Agustín de la Emboscada, obligandoles a defender el presidio inmediato llamado Arecutagua con lo cual quedaron a cubierto el Salado y los campos de Tapua que entonces eran el término poblado de la Provincia en la banda Norte. Esto sucedió en 1742, pero no se formalizo hasta el 1744"'57.

Esta versión debe ser revisada, corregida y completada con otros datos, ya que no parece aventurado suponer que los mulatos pobladores de San Agustín de la Emboscada procedían en gran parte del propio Castillo de San Agustín de Arecutacuá. En primer lugar, la misma coincidencia del nombre (San Agustín) puede ser indicio de un traslado de pobladores que han mantenido la advocacion a su patrono, llevando consigo la pequeña imagen o representación del santo.

Los datos aquí manejados hacen obligado corregir la versión de Azara y concluir que la fundación de Emboscada pudo deberse primordialmente no a la necesidad de defender Arecutacuá, sino por el contrario, a la necesidad de trasladar su población.

Así se deduce del informe ya citado de 28 de junio de 1738, donde el Mariscal de Campo Sebastian Montiel se refiere a "bastantes familias de mulatos libres que de continuo han estado y estan en él". El informe termina aconsejando que "se muden a otro parage comodo" 58 . El Cavildo es de igual opinión a finales de 1738, es decir, poco más de tres años antes de la fundación de Emboscada.

Es inevitable pensar que al menos una buena parte de los pobladores "gente amparada, negra y mulata” que se establecieron en San Agustín de La Emboscada eran aquellas "bastantes familias de mulatos libres" que todavía en 1738 habitaban San Agustín de Arecutacuá y que habían de ser mudados a "otro parage comodo".

En todo caso, es difícil admitir que la defensa del Castillo de San Agustín de Arecutacuá fuera el motivo primordial para la fundación de Emboscada, cuando en el citado informe de 28 de junio de 1738 se afirma la inutilidad defensiva del castillo porque los indios pasaban distantes de él por el río, o venían por tierra.

Además, la obligación de guarnecer Arecutacuá que, según Azara, tuvieron los vecinos de Emboscada, y que habría sido el movil de su fundación, tampoco se ve confirmada en documentos posteriores, pues sabemos que los 19 soldados

${ }^{57}$ AZARA, Félix: "Geografía física y esférica de las Provincias del Paraguay y Misiones Guaraníes”, Anales del Museo Nacional de Montevideo, 1904, pp. 48-49.

${ }^{58}$ ANA, SH, vol. 119, n 14. 
que se mantenían como guardia de Arecutacuá en marzo de 1790 no eran de Emboscada, sino de Pirayu ${ }^{59}$

Tratando de hacer compatibles todos los datos con la versión de Azara, lo más verosimil es suponer que, ante la necesidad de trasladar a los pobladores de San Agustín de Arecutacuá porque la Provincia carecía de medios para mantenerlos como se hizo durante los primeros años, y porque las tierras pedregosas de aquella zona no permitían el autoabastecimiento de la guarnición, Rafael de la Moneda decidiera fundar una población relativamente próxima para que la zona no quedara totalmente desguarnecida. ${ }^{60}$

En conclusión, los datos documentales existentes hacen pensar que la presencia hasta hoy de una mayoritaria población mulata en San Agustín de la Emboscada, caso único en Paraguay, tiene sus orígenes precisamente en la población del castillo de Arecutacuá, en aquellos "mulatos libres" que en 1725 se habían recogido de toda la provincia.

\subsection{Castillo y Presidio}

Como indicamos al principio, originariamente los términos "castillo" y "presidio" son practicamente sinónimos. Según Covarrubias: "comunmente llamamos presidio al castillo o fuerza donde ay gente de guarnicion" ${ }^{\prime}$. Posteriormente, debido a la costumbre de confinar en estas guarniciones a los apresados por la justicia, "presidio" paso a tomar el sentido actual de "lugar donde se encierra a los castigados por la Justicia" o "establecimiento carcelario".

También San Agustín de Arecutacuá cumplió esta doble función expresada en el termino "presidio".

En Arecutacuá fue recluido Don José de Avalos de Mendoza (que había gobernado la Provincia) por orden del entonces Governador Diego de los Reyes Balmaseda en el año 1719, hecho este muy significativo entre el cúmulo de acontecimientos que desencadenaron las Revoluciones Comuneras. Ya que José de Avalos .." Aunque guardado por oficiales del partido del Gobernador mantenía comunicación por medio de Tomás Cardenas su familiar que con pretexto de divertir

${ }^{59}$ ANA, NE, vol. 3374.

${ }^{60}$ "El Castillo de Arecutacuá viene a ser como la raíz histórica de la fundación de la Emboscada y más tarde será como la razón de ser, de existir, de esta población” BLUJAKI, Agustín: "Pueblo de pardos...", op. cit. p. 147. La importante población de pardos libres en Arecutacuá, y sobre todo, la concentración de "los mulatos libres que ai en la provincia" el año 1725, confirman plenamente esta afirmación.

${ }^{61}$ Vid. nota ${ }^{\circ} 3$ 
le entraba disfrazado de gracioso que en la provincia llaman Cambaranga y el fue quien presento su capitulación ${ }^{62}$ a la Real Audiencia" 63.

No fue Don José de Avalos el único recluido en el castillo de Arecutacuá. Otro destacado protagonista de los violentos acontecimientos de aquella época, Don Ramón de Llanas, fue también confinado en Arecutacuá hacia el año de 1730, por orden del Juez Pesquisidor D. Matias de Angles. ${ }^{64}$

En este aspecto, también Arecutacuá supone un precedente histórico significativo para Emboscada, pues allí está situado hasta hoy el principal penal del Paraguay, muy conocido por haber sido lugar de reclusión para los detenidos políticos durante los largos periodos de régimen dictatorial.

Fecha de recepción: 20 de septiembre de 2014

Fecha de aceptación: 28 de noviembre de 2014

${ }^{62}$ Las acusaciones presentadas ante la Real Audiencia (parte de 19 do Diciembre de 1721) contra Reyes, fueron: "Que abría y estancaba las cartas de comunicación a su arbitrio [...] Que tenía comercios y monopolios, comprando con mercadería la hierba a su arbitrio [...] Que impuso la gavela de 3 arrobas por cada 20 cargas que al estilo del país es un treinta por ciento (Aguirre señala que solo es un 3\%) [...]

Que habría matado mil personas de indios accion la mas sensible por estar amparados bajo el Real nombre". AGUIRRE, Francisco de: Diario, op.cit, p. 478.

${ }^{63}$ Ibídem, p. 475.

${ }^{64}$ Ibid., p. 489. 